\title{
Psychological Well-Being of COVID Positive Patients During Quarantine in a South Indian Private Hospital
}

Author's Contribution:

A - Study design;

B - Data collection;

C - Statistical analysis;

D - Data interpretation;

E - Manuscript preparation;

F - Literature search;

G - Funds collection

Background and Aim of Study:

Material and Methods:

Results:

Conclusions:

Keywords:

Copyright:

DOI and UDC

Conflict of interests:

Peer review:

Source of support:

Information about the author:

\author{
Chakrabarti S. ${ }^{1 \mathrm{ABCDEFG}}$ (D) \\ ${ }^{1}$ Saveetha Medical College and Hospital, Chennai, India \\ Received: 11.02.2021; Accepted: 11.05.2021; Published: 30.06.2021
}

\section{Abstract}

The Coronavirus disease 2019 (COVID-19) pandemic has led to unparallel hazards to mental health globally. Many countries around the world have introduced quarantine measures. Quarantine has changed not only the plans of most people, but also their way of life. The greatest impact of quarantine is experienced by COVID positive patients who are isolated in a hospital.

The aim of the study: to explore psychological well-being of COVID positive patients during quarantine in a private hospital.

In this study, 100 patients who were COVID positive were requested to fill the Quality of Life Questionnaire. A pre-validated questionnaire was used to assess the depression score amongst COVID positive patients. The analysis of the answers and respondent opinions was conducted using the Pearson method, which produced statistically relevant results.

The studied aspects of mental health patients: sleep, appetite, crying spells; happiness and hope for the future; ability to concentrate and focus and getting disturbed easily by trivia; support received from family and friends; overall outlook of life and ability to stay happy in solitude. As a result, qualitative indicators of the patients' mental health during quarantine in a private hospital were obtained.

The data obtained showed that patients managed to stay happy and eat well but they talked less, had disturbed sleep and did not look forward towards a hopeful future. Some were able to shake away the blues with family, friends on Online Media but some got depressed and got crying spells and thought that their life was a failure. The study concluded that patients on quarantine were often depressed. Many patients might benefit if psychological counselling and support are employed during quarantine measures.

mental health, psychological well-being, quarantine, pandemic, COVID-19

(C) 2021 Chakrabarti S. Published by Archives of International Journal of Science Annals

DOI https://doi.org/10.26697/ijsa.2021.1.5 UDC 159.

The author declares that there is no conflict of interests

Double-blind review

This research did not receive any outside funding or support

Chakrabarti Sudakshina - https://orcid.org/0000-0003-1344-8317; sudhianat@gmail.com; Doctor of Medicine, Associate Professor of Anatomy, Covid Duty Doctor, Saveetha Medical College and Hospital, Chennai, India. 


\section{Introduction}

In December 2019 there was a sudden rise in cases of pneumonia in Wuhan city, China which was later designated as Coronavirus disease by the World Health Organization (WHO) on February 11, 2020. This Coronavirus is identified as a novel strain of coronavirus that shares $79 \%$ of genetic similarity with SARS-CoV from the SARS outbreak 2003. On March 11, 2020, the WHO declared the outbreak a global pandemic (Anand et al., 2020). This outbreak has changed various aspects of the economy resulting in vast decline in tourism, aviation, agriculture and financial sectors of the country (Nicola et al., 2020). The consequences of this pandemic affected the physical and mental health of individuals more than the world anticipated (Brooks et al., 2020; Fiorillo \& Gorwood, 2020; Hanna et al., 2018; Lima et al., 2020). Resulting COVID-19 has required many countries across the globe to implement early quarantine measures as the fundamental disease control tool. Mental disorders, such as anxiety, depression, are attributed to risk factors including loneliness, frustration, which is inevitable in the majority of the population during quarantine (Kang et al., 2020; Shigemura et al., 2020; Park, S.-C., \& Park, 2020). Altruistic behavior towards self-isolation and voluntary quarantine should be encouraged after proper clarification through mass communication to minimize distress and long-term complications of imposed quarantine.

The aim of the study. To explore psychological wellbeing of COVID positive patients during quarantine in a private hospital.

\section{Materials and Methods}

In this study 100 patients who were COVID-19 diagnosed as positive by RTPCR, were requested to fill the questionnaire. This study was approved by the Ethical and Research Board. Voluntary written informed consent was obtained in all cases. Permission was obtained from the Ethical Committee at Saveetha Medical College and Hospital, Chennai, India. A validated questionnaire was used to assess the depression score amongst COVID-19 positive patients. This study was conducted from May 2020 to September 2020.

\section{Sample Size and Collection}

A total of 100 COVID-19 positive patient in age group 18-60 years by RTPCR who underwent quarantine were requested to fill the Google questionnaire form "Psychosocial Impact of COVID-19 Pandemic" after written informed consent in local language. The participation was voluntary. A total of 68 responses were received and were obtained in the study. The prevalidated DSM 4 (ICDS) questionnaires were used to assess the depression score amongst COVID-19 positive patients and data was analyzed using automated Google pie charts and Percentages. Patients with a pre-existing psychiatric illness those who are not willing to be a part of the study were excluded from the study.

Data Analysis

Data was analyzed for calculating the percentage of patient with different depression score. Automated Graphs were used to analyze the data.

The analysis of the answers and respondent opinions was conducted using the Pearson method, which produced statistically relevant results.

\section{Results \\ Questionnaires were sent to 100 patients out of whom 68 responded. The summary results of the respondents' answers according to the developed questionnaire are shown in Table 1.}

\section{Table 1}

Summary Results of Respondents' Answers According to the Developed Questionnaire

\begin{tabular}{|c|c|c|c|c|c|}
\hline \multirow[t]{2}{*}{ Queries for participants } & \multicolumn{5}{|c|}{$\begin{array}{l}\text { Distribution of the participants number according to the responses } \\
\text { (people/\%) }\end{array}$} \\
\hline & A & $\mathrm{B}$ & $\mathrm{C}$ & $\mathrm{D}$ & Total \\
\hline 1. I was bothered by things that really don't bother me & $31 / 47.0$ & $19 / 28.8$ & $7 / 10.6$ & 9/13.6 & $66 / 100.0$ \\
\hline 2. I could not get going & $29 / 44.6$ & $24 / 36.9$ & $6 / 9.3$ & $6 / 9.2$ & $65 / 100.0$ \\
\hline 3. I felt like people dislike me & $43 / 65.2$ & $16 / 24.2$ & $3 / 4.5$ & $4 / 6.1$ & $66 / 100.0$ \\
\hline 4. I felt sad & $28 / 41.8$ & $19 / 28.4$ & $12 / 17.9$ & $8 / 11.9$ & $67 / 100.0$ \\
\hline 5. I had crying spells & $48 / 73.8$ & $10 / 15.4$ & $6 / 9.2$ & $1 / 1.6$ & $65 / 100.0$ \\
\hline 6. I enjoyed life & $11 / 16.6$ & $7 / 10.6$ & $10 / 15.2$ & $38 / 57.6$ & $66 / 100.0$ \\
\hline 7.People were unfriendly & $42 / 63.6$ & $19 / 28.8$ & $4 / 6.5$ & $1 / 1.1$ & $66 / 100.0$ \\
\hline 8. I felt lonely & $31 / 46.3$ & $20 / 29.9$ & $7 / 10.4$ & $9 / 13.4$ & $67 / 100.0$ \\
\hline 9. I had trouble keeping my mind on what I was doing & $31 / 47.0$ & $21 / 31.8$ & $5 / 7.6$ & $9 / 13.6$ & $66 / 100.0$ \\
\hline 10. I did not feel like eating; my appetite was poor & $34 / 51.5$ & $17 / 25.8$ & $7 / 10.6$ & $8 / 12.1$ & $66 / 100.0$ \\
\hline $\begin{array}{l}\text { 11. I felt that I could not shake off the blues with the } \\
\text { help from my family or friends }\end{array}$ & $47 / 71.2$ & $13 / 19.7$ & $3 / 4.2$ & $3 / 4.9$ & $66 / 100.0$ \\
\hline 12. I felt I was just as good as other people & $3 / 4.4$ & $5 / 7.3$ & $4 / 5.9$ & $56 / 82.4$ & $68 / 100.0$ \\
\hline 13. I felt that everything I did was an effort & $20 / 30.3$ & $11 / 16.6$ & $5 / 7.6$ & $30 / 45.5$ & $66 / 100.0$ \\
\hline 14. I talked less than usual & $28 / 41.8$ & $15 / 22.4$ & $7 / 10.4$ & $17 / 25.4$ & $67 / 100.0$ \\
\hline 15. I was happy & $11 / 16.7$ & $4 / 6.0$ & $7 / 10.6$ & $44 / 66.7$ & $66 / 100.0$ \\
\hline 16. My sleep was restless & $25 / 37.3$ & $23 / 34.3$ & $11 / 16.5$ & $8 / 11.9$ & $67 / 100.0$ \\
\hline 17. I felt fearful & $38 / 56.7$ & $15 / 22.4$ & $6 / 9.0$ & $8 / 11.9$ & $67 / 100.0$ \\
\hline 18. I thought my life had been a failure & $52 / 78.8$ & $5 / 6.9$ & $4 / 6.7$ & $5 / 7.6$ & $66 / 100.0$ \\
\hline 19. I felt hopeful about the future & $6 / 8.8$ & $10 / 14.7$ & $8 / 11.8$ & $44 / 64.7$ & $68 / 100.0$ \\
\hline 20. I felt depressed & $49 / 73.1$ & $5 / 7.5$ & $4 / 6.0$ & $9 / 13.4$ & $67 / 100.0$ \\
\hline
\end{tabular}


Figures 1 to 20 show the graphical representation of number of patients with different dimensions of mental health. The aspects of sleep, appetite, crying spells were recorded. The dimensions of happiness and hope for the future were analyzed. Ability to concentrate and focus and getting disturbed easily by trivia was also studied. The support received from family and friends was documented. Overall outlook of life and ability to stay happy in solitude was assessed.

According to Figure 1 a total of $47.0 \%$ respondents rarely felt that they were bothered by the things that really don't bother them; $28.8 \%$ - sometimes felt such a state; only $13.6 \%$ respondents were bothered by the things that usually don't bother them.

Figure 1

Distribution of Respondents' Answers to Query 1

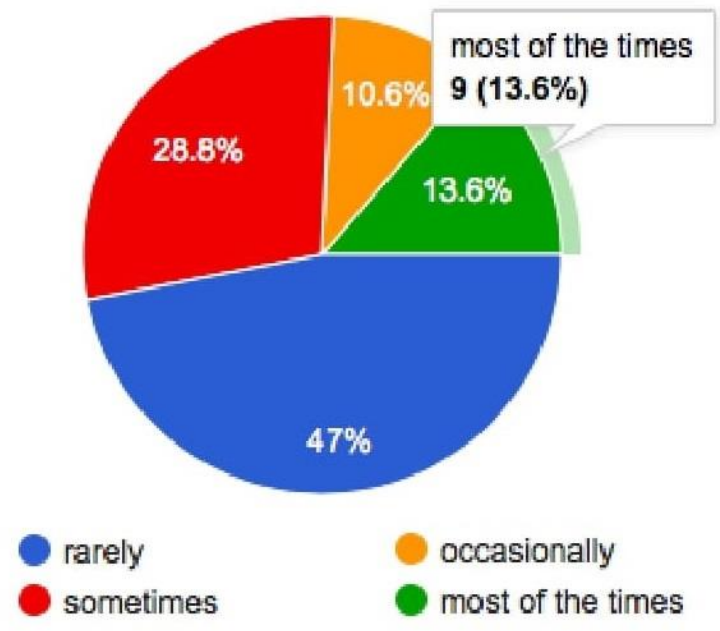

Figure 2 shows that respondents felt as they could not get going: rarely $-44.6 \%$, sometimes $-36.9 \%$, occasionally $-9.3 \%$, most of the time $-9.2 \%$.

Figure 2

Distribution of Respondents' Answers to Query 2

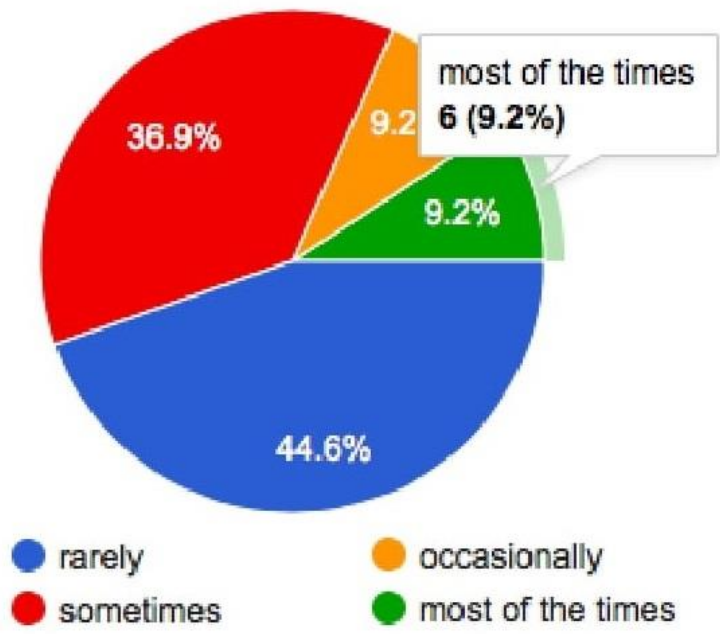

A total of $65.2 \%$ respondents felt that people rarely disliked them, only $6.1 \%$ respondents felt such a state most of the time (Figure 3).
Figure 3

Distribution of Respondents' Answers to Query 3

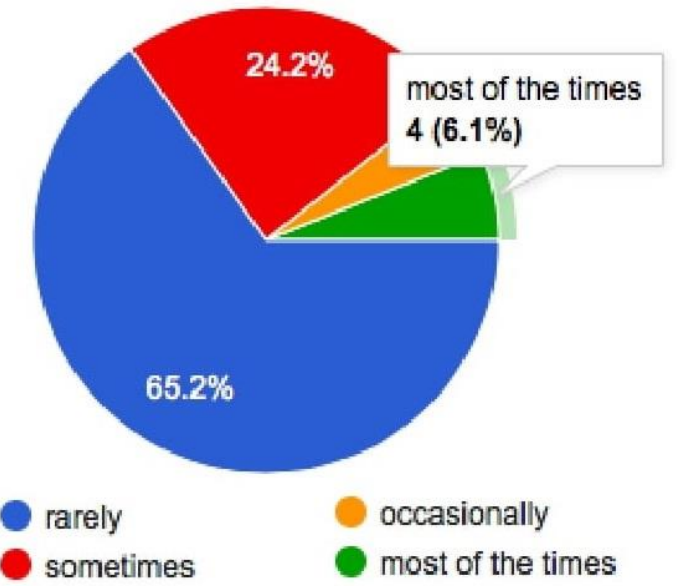

The respondents answered about the sad feeling as follows (Figure 4): rarely $-41.8 \%$, sometimes $-28.4 \%$, occasionally $-17.9 \%$, most of the time $-11.9 \%$.

\section{Figure 4}

Distribution of Respondents' Answers to Query 4

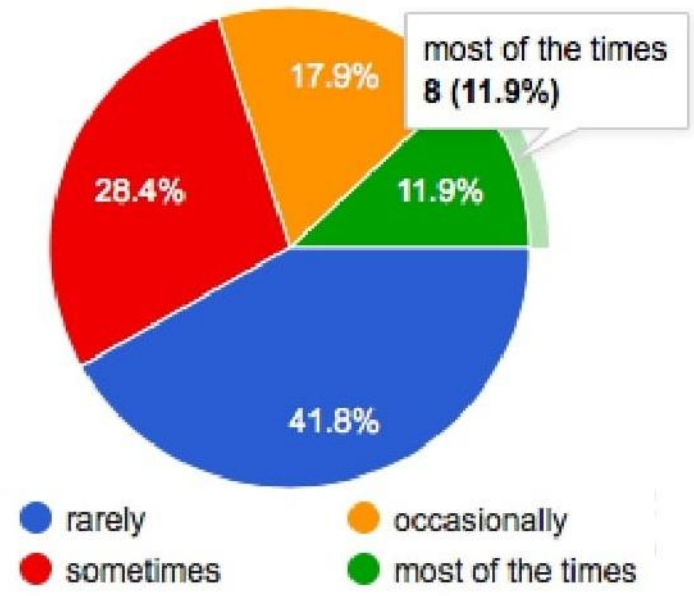

Figure 5 shows that $73.8 \%$ respondents rarely had crying spells, $15.4 \%$ - sometimes had such a state.

\section{Figure 5}

Distribution of Respondents' Answers to Query 5

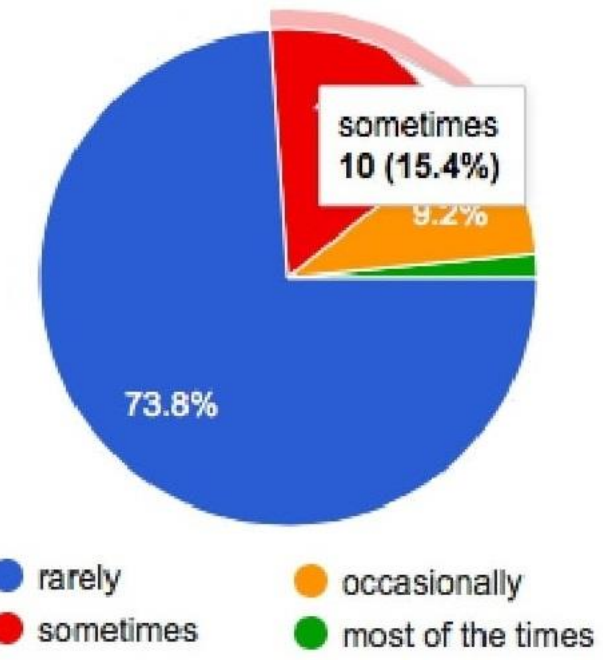


Most of the respondents (57.6\%) answered to have enjoyed their life during the quarantine period, but $16.6 \%$ rarely enjoyed their life in the quarantine period (Figure 6).

\section{Figure 6}

Distribution of Respondents' Answers to Query 6

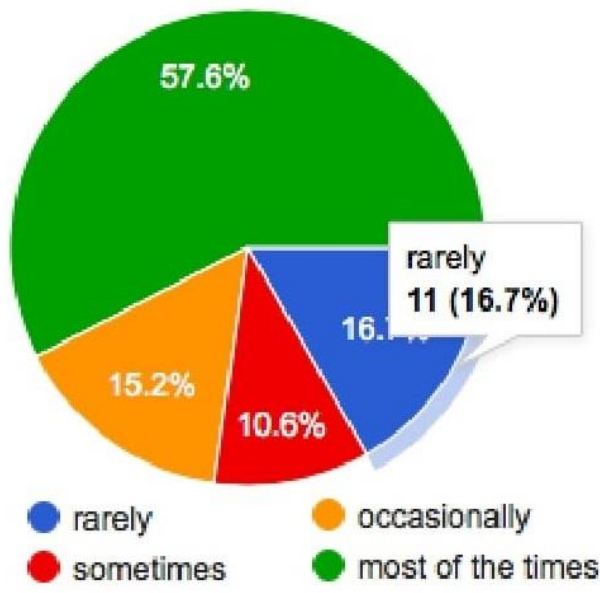

About $63.6 \%$ respondents rarely felt that people were unfriendly to them, $28.8 \%$ of respondents felt that people sometimes were unfriendly to them (Figure 7).

\section{Figure 7}

Distribution of Respondents' Answers to Query 7

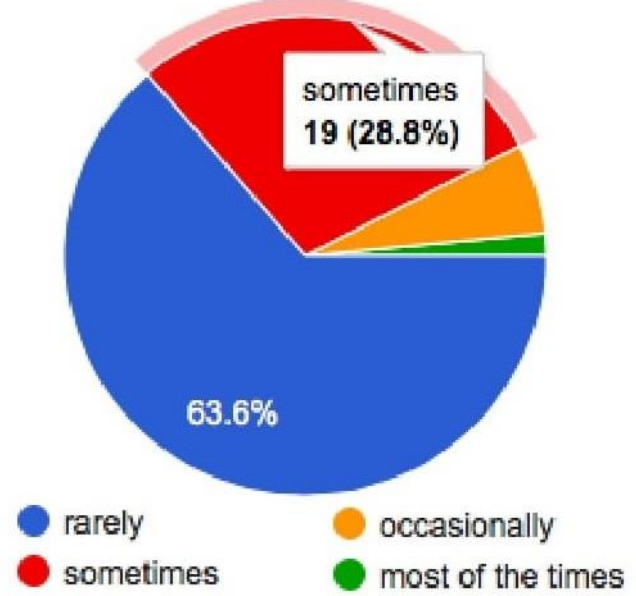

A total of $13.4 \%$ respondents felt lonely for most of the time; $46.3 \%$ - rarely felt lonely; $29.9 \%$ - sometimes felt lonely (Figure 8).

\section{Figure 8}

Distribution of Respondents' Answers to Query 8

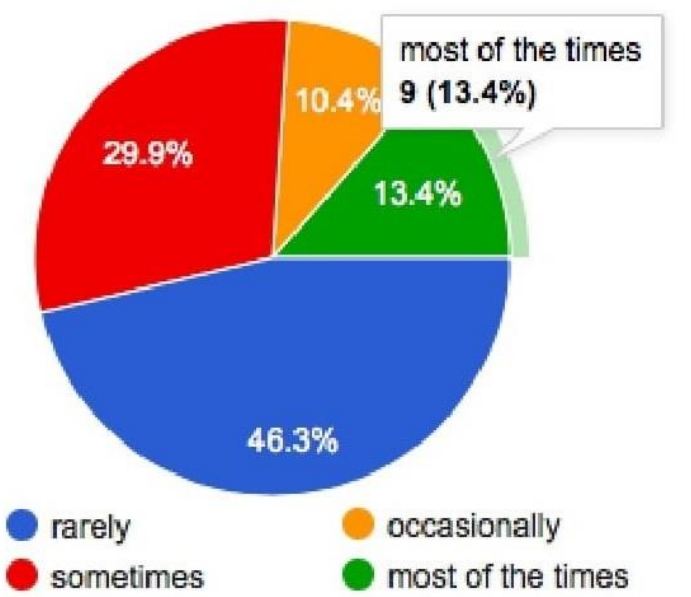

A lot of people occupied themselves with other activities like WhatsApp, Twitter, Facebook and other online social media. Figure 9 shows that $13.6 \%$ respondents were unable to concentrate whatever they were doing most of the time; $47.0 \%$ respondents rarely had trouble keeping their mind on what they were doing.

\section{Figure 9}

Distribution of Respondents' Answers to Query 9

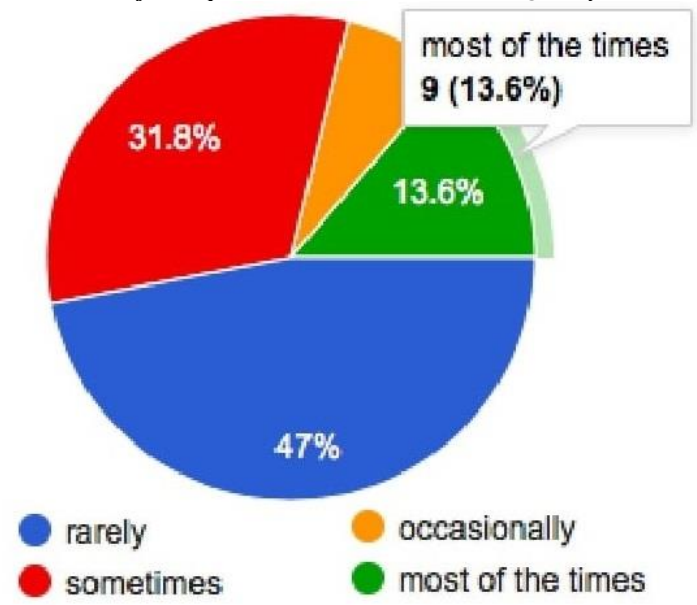

Figure 10 shows that $51.5 \%$ respondents had a good appetite, but $12.1 \%$ respondents had poor appetite most of the time.

\section{Figure 10}

Distribution of Respondents' Answers to Query 10

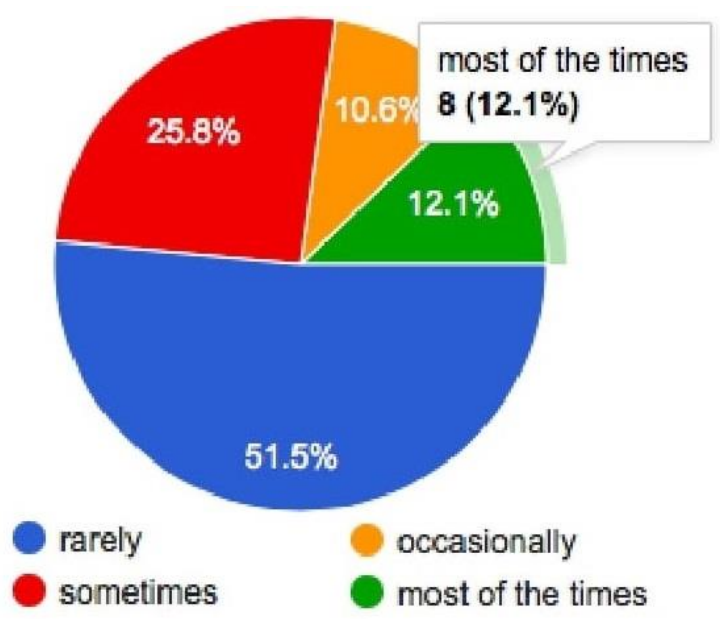

Figure 11 shows that $71.2 \%$ respondents rarely felt that they could not shake off the blues with the help from family and friends, and $19.7 \%$ respondents agreed that they were able to shake away the blues with the help of family and friends sometimes. 


\section{Figure 11}

Distribution of Respondents' Answers to Query 11

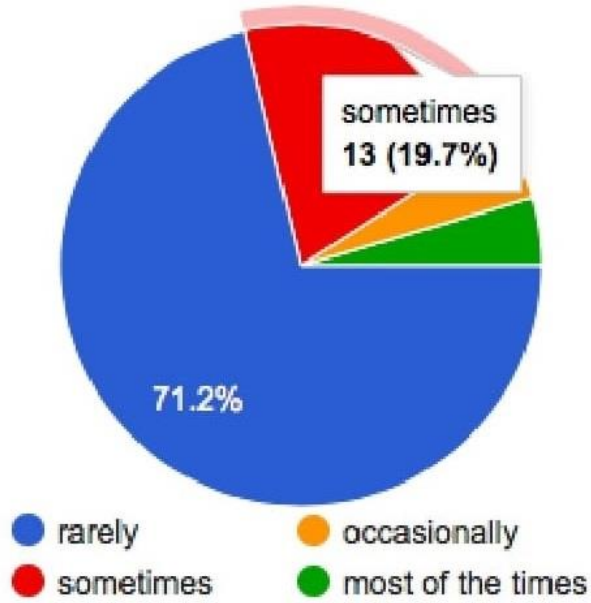

A total of $82.4 \%$ respondents felt that they were just as good as other people, but $4.4 \%$ respondents rarely felt that they were just as good as others (Figure 12).

\section{Figure 12}

Distribution of Respondents' Answers to Query 12

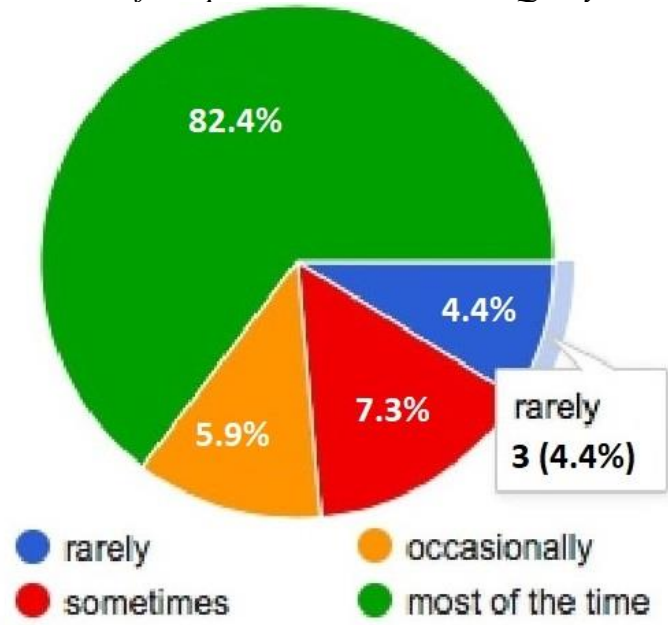

Figure 13 shows that $45.5 \%$ respondents felt that everything they did was an effort most of the time, $30.3 \%$ respondents rarely felt such a state.

\section{Figure 13}

Distribution of Respondents' Answers to Query 13

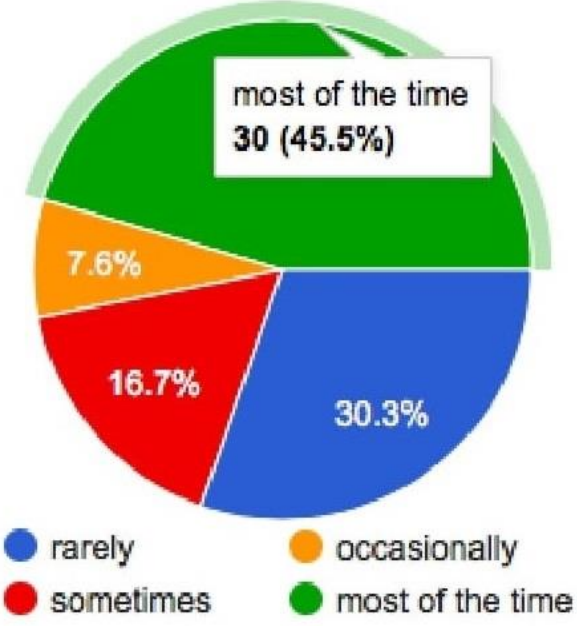

A total of $41.8 \%$ respondents rarely felt that they talked less than usual, $25.4 \%$ respondents -most of the time felt such a state (Figure 14).

\section{Figure 14}

Distribution of Respondents' Answers to Query 14

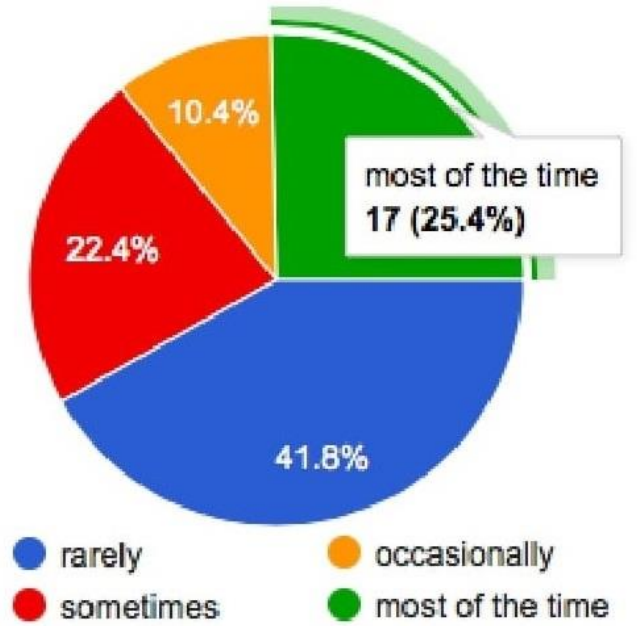

Figure 15 shows that most of the respondents $(66.7 \%)$ felt happy most of the time, but $16.7 \%$ - were unhappy.

Figure 15

Distribution of Respondents' Answers to Query 15

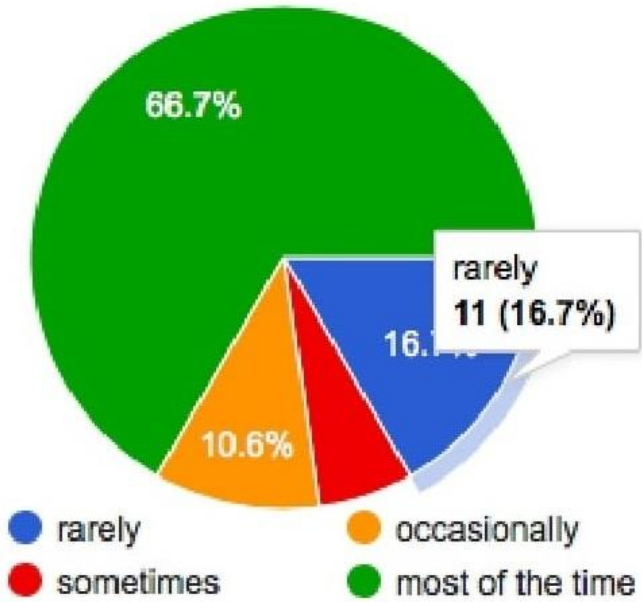

According to Figure $1637.3 \%$ respondents rarely, 34.3\% respondents sometimes had restless sleep.

Figure 16

Distribution of Respondents' Answers to Query 16

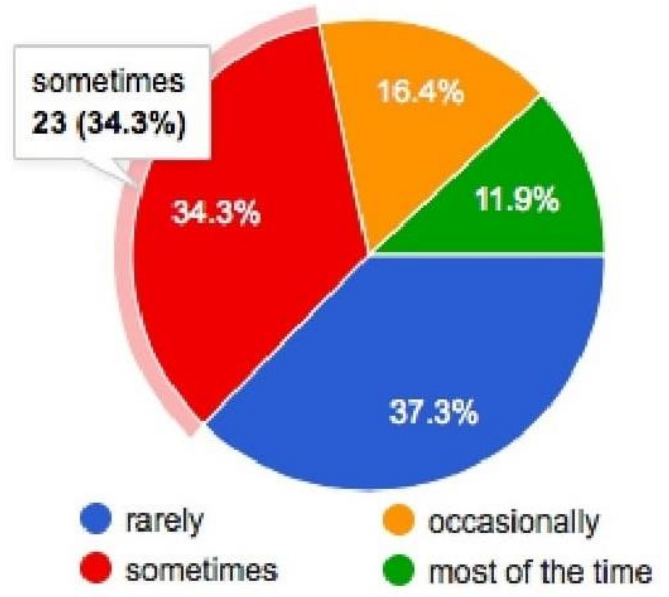


Figure 17 shows that $11.9 \%$ respondents felt fearful most of the time, $56.7 \%$ - rarely felt fearful.

Figure 17

Distribution of Respondents' Answers to Query 17

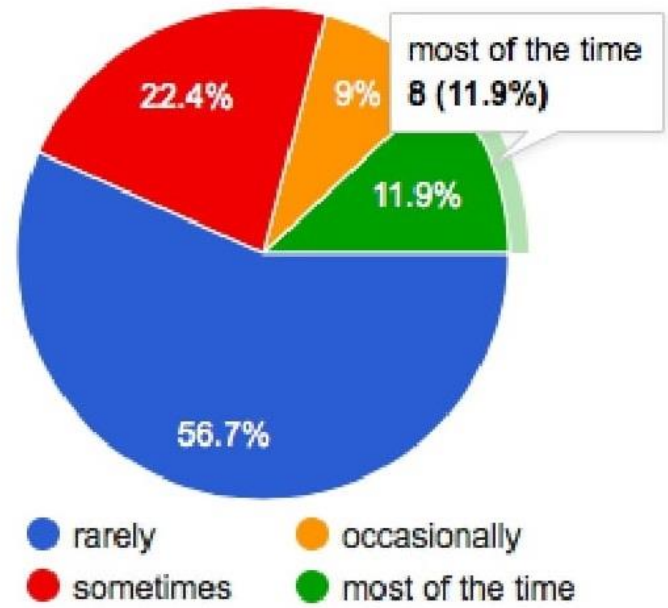

A total of $78.8 \%$ respondents rarely thought that their life had been a failure, but $7.6 \%$ - thought that their life had been a failure most of the time (Figure 18).

\section{Figure 18}

Distribution of Respondents' Answers to Query 18

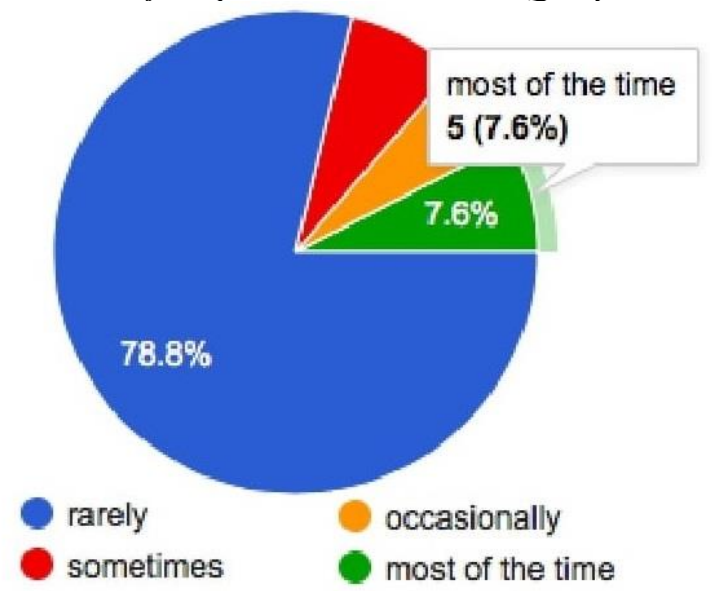

Figure 19 shows that $64.7 \%$ respondents most of the time were hopeful about the future, but $8.8 \%$ - rarely felt hopeful.

\section{Figure 19}

Distribution of Respondents' Answers to Query 19

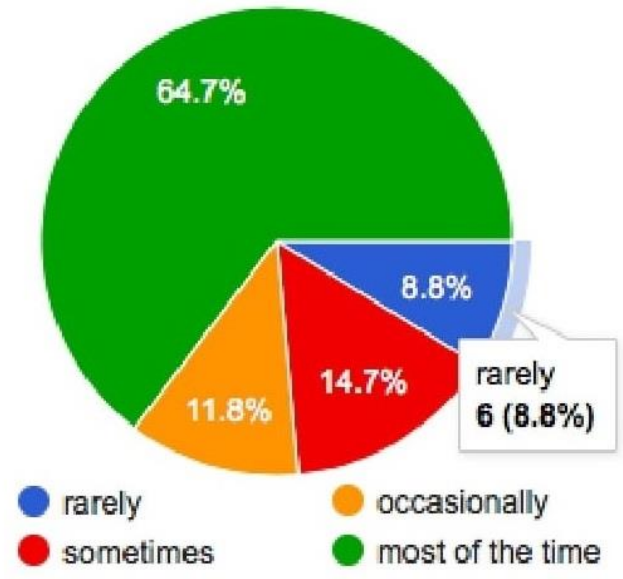

Figure 20 shows that a few respondents (13.4\%) actually felt depressed, while $73.1 \%$ - rarely felt depressed.

Figure 20

Distribution of Respondents' Answers to Query 20

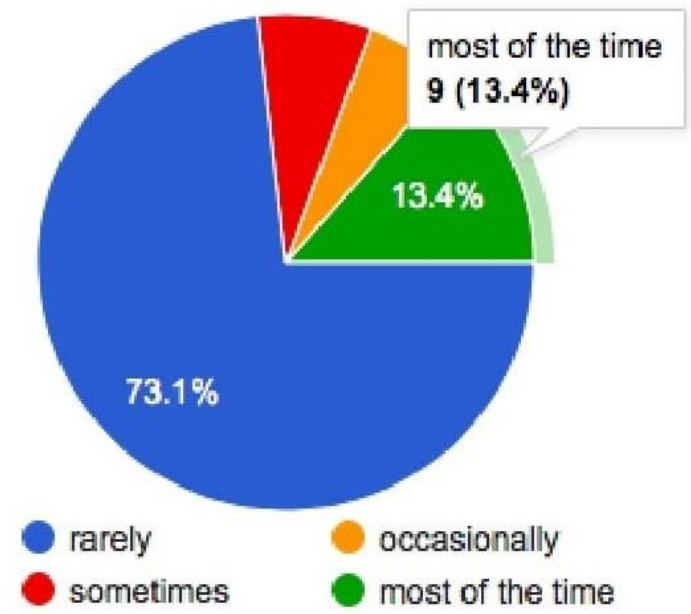

Despite the fact that the study was conducted in India, its results can be useful to scientists for research on the COVID problem around the world.

\section{Discussion}

Our study explored the mental health status of the general population amidst the COVID-19 pandemic. Generally, there is a higher prevalence of symptoms of adverse psychiatric outcomes among the public when compared to the prevalence before the pandemic (Huang et al., 2019). The quarantine imposed due to the coronavirus outbreak adversely influenced people's economy because of an increase in the rate of unemployment. This led to an increased financial crisis among people and decrease in the quality of life. All these factors can put individuals at greater risk for developing adverse psychological symptoms.

Xiong et al. (2020) found that there are relatively high rates of symptoms of anxiety depression and posttraumatic stress disorders, psychological distress and stress in the general population during the COVID-19 pandemic in China. But in our study, most of the people (13.4\%) felt depressed and $11.9 \%$ had sleep disturbances most of the time.

According to a study by Brooks et al. (2020), the severity of stress related symptoms will depend upon the quarantine duration and extent, the fear of being infected, feeling lonely. In our study, we found $11.6 \%$ of people felt fearful most of the time and $13.4 \%$ of people felt lonely most of the time.

According to Zhang and Ma (2020), they found a higher prevalence of insomnia, anxiety, depressive symptoms, somatization, and obsessive-compulsive symptoms in mental health staff.

A systematic review and meta-analysis (including studies from 2000 to 2014) showed an impact of an epidemic/pandemic on the mental health of health care professionals, as "probable" percentage of cases (Vyas et al., 2016). In this review, psychological distress was assessed in 13 studies, with an average rate among exposed HCPs of approximately $40 \%$ (range: 11-75\%). Insomnia was assessed in four studies, with an average 
rate among exposed HCPs of approximately $39 \%$ (range: 30-52\%). Posttraumatic stress disorder (PTSD) symptoms were assessed in 19 studies, with an average rate of approximately $21 \%$ (range: $10-33 \%$ ), of whom $40 \%$ reported persistently high PTSD symptoms 3 years after exposure. Meta-analytic results showed effects were small, $(\mathrm{SMD}=0.12,95 \% \mathrm{CI}=-0.23$ to 0.47$)$, but not significant. Depression symptoms were measured in 8 studies, with an average rate of approximately $46 \%$ (range: $23-74 \%$ ), of whom up to $9 \%$ reported severe levels. $11 \%$ were clinically diagnosed 1 month after the disease outbreak. Meta-analytic results showed effects were moderate $(\mathrm{SMD}=0.40,95 \% \mathrm{CI}=0.24-0.51)$ and significant. Anxiety symptoms were assessed in fourteen studies. The average rate was approximately $45 \%$ (range: 19-77\%). Meta-analytic results showed effects were small, $(\mathrm{SMD}=0.08,95 \% \mathrm{CI}=-0.09$ to 0.25$)$ and not significant. In our study $67.7 \%$ of the people felt happy and $75 \%$ of the people were hopeful about the future.

One systematic review (Brooks et al., 2018) synthesizing the social and occupational factors affecting the mental health of HCPs covered the literature up to 2015 and included 22 studies, all of which had investigated the SARS epidemic. Brooks et al. (2018) identified six organizational and four social factors as showing an influence on mental health outcomes. For this rapid review, no further evidence of social and organizational factors published after 2015 was identified amongst our accepted papers. Below is a brief summary of the organizational and social factors found by Brooks et al. (2018) and associated data can be found in the study (Brooks et al., 2018). Further predictors, beyond organizational and social factors, may also influence the impact of epidemics/pandemics on mental health.

In another review it was observed that subsyndromal psychological states were common during COVID pandemic. Anxiety, depression and self-reported stress are some of the commonly reported symptoms (Rajkumar, 2020).

A study from Iran has revealed certain causes of stress and mental morbidity during COVID can be resulting from misinformation, social isolation and unpredictable nature of the disease (Zandifar \& Badrfam, 2020).

Western countries have incorporated psychological interventions into their protocols for COVID outbreaks, this has not yet happened in countries such as China, India, other developing nations leading to increased prevalence of stress-related disorders in COVID affected persons. There is definitely a need for development of intervention strategies in managing COVID affected patients in hospital wards (Duan \& Zhu, 2020).

Lima et al. (2020) have pointed out anxiety and depression as the most important COVID related psychological morbidity among general population and also among patients. This calls for training among health care personal for dealing COVID patients and use of technology in delivering mental care.

Resistance to post-traumatic stress reactions of vulnerable groups engaged in pandemic COVID-19 liquidation has been studied by Melnyk, Stadnik, and Pypenko (2020).
Health anxiety is the term used by some authors which is a state of mind where certain body functioning mechanisms can be misinterpreted as symptoms of infectious pandemic disease. With COVID-19 media coverage, misinformation and exaggerated information can result in excessive health anxiety not only in COVID patients but also among general population. This can result in maladaptive behaviors among masses like hoarding items, refusing treatments or making multiple visits to health care facilities etc. (Asmundson \& Taylor, 2020a; 2020b).

\section{Conclusions}

The present study suggests that there is an increased stress during isolation and quarantine during pandemics. Patients manage to stay happy and eat well but they talk less, have disturbed sleep and do not look forward towards a hopeful future. Some are able to shake away the blues with family, friends on Online Media but a few do get depressed and get crying spells and think that their life is a failure. Patients often realize that the disease is difficult to cure and whatever they do is just an effort and not a cure. Many patients might benefit if psychological counselling and support are employed during quarantine measures.

\section{Acknowledgements}

The author acknowledges the management of Saveetha Medical College and Research Associates in helping out with data collection.

\section{Ethical Approval}

The present study was approved by the Institutional Human Ethics Committee, Saveetha Medical College and Hospital, Chennai, India (SMCH/07/116/20 from 03.07.2020)

\section{Funding Source}

This research did not receive any outside funding or support.

\section{References}

Anand, K. B., Karade, S., Sen, S., \& Gupta, R. M. (2020). SARS-CoV-2: Camazotz's curse. Medical Journal Armed Forces India, 76(2), 136-141. https://doi.org/10.1016/j.mjafi.2020.04.008

Asmundson, G. J. G., \& Taylor, S. (2020a). Coronaphobia: Fear and the 2019-nCoV outbreak. Journal of Anxiety Disorders, 70, 102196. https://doi.org/10.1016/j.janxdis.2020.102196

Asmundson, G. J. G., \& Taylor, S. (2020b). How health anxiety influences responses to viral outbreaks like COVID-19: What all decision-makers, health authorities, and health care professionals need to know. Journal of Anxiety Disorders, 71, 102211. https://doi.org/10.1016/j.janxdis.2020.102211

Brooks, S. K., Dunn, R., Amlôt, R., Rubin, G. J., \& Greenberg, N. (2018). A systematic, thematic review of social and occupational factors associated with psychological outcomes in 
healthcare employees during an infectious disease outbreak. Journal of Occupational and Environmental Medicine, 60(3), 248-257. https://doi.org/10.1097/JOM.0000000000001235

Brooks, S. K., $\quad$ Webster, R. K., $\quad$ Smith, L. E., Woodland, L., Wessely, S., Greenberg, N., \& Rubin, V. (2020). The psychological impact of quarantine and how to reduce it: Rapid review of the evidence. The Lancet, 395(10227), 912920. 6736(20)30460-8 https://doi.org/10.1016/S0140-

Duan, L., \& Zhu, G. (2020). Psychological interventions for people affected by the COVID-19 epidemic. The Lancet Psychiatry, 7(4), 300-302. https://doi.org/10.1016/S2215-0366(20)30073-0

Fiorillo, A., \& Gorwood, P. (2020). The consequences of the COVID-19 pandemic on mental health and implications for clinical practice. European Psychiatry, 63(1), E32. https://doi.org/10.1192/j.eurpsy.2020.35

Hanna, F., Barbui, C., Dua, T., Lora, A., van Regteren Altena, M., \& Saxena, S. (2018). Global mental health: how are we doing? World Psychiatry, 17(3), 367-368. https://doi.org/10.1002/wps.20572

Huang, Y., Wang, Yu., Wang, H., Liu, Z., Yu, X., Yan, J., Yu, Y., Kou, C., Xu, X., Lu, J., Wang, Z., He, S., Xu, Y., He, Y., Li, T., Guo, W., Tian, H., Xu, G., Xu, X. ... Wu, Y. (2019). Prevalence of mental disorders in China: A cross-sectional epidemiological study. The Lancet Psychiatry, 6(3), 211-224. https://doi.org/10.1016/S2215-0366(18)30511-X

Kang, L., Li, Y., Hu, S., Chen, M., Yang, C., Yang, B. X., Wang, Y., Hu, J., Lai, J., Ma, X., Chen, J., Guan, L., Wang, G., Ma, H., \& Liu, Zh. (2020). The mental health of medical workers in Wuhan, China dealing with the 2019 novel coronavirus. The Lancet Psychiatry, 7, E14. https://doi.org/10.1016/S22150366(20)30047-X

Lima, C. K. T., Carvalho, P. M. M., Lima, I. A. A. S., Nunes, J. V. A. O., Saraiva, J. S., de Souza, R. I., $\quad$ da Silva, C. G. L., \& Neto, M. L. R. (2020). The emotional impact of Coronavirus 2019-nCoV (new Coronavirus disease). Psychiatry Research, 287, 112915. https://doi.org/10.1016/j.psychres.2020.112915

Nicola, M., Alsafi, Z., Sohrabi, C., Kerwan, A., AlJabir, A., Iosifidis, C., Agha, M., \& Agha, R. (2020). The socio-economic implications of the coronavirus pandemic (COVID-19): A review. International Journal of Surgery, 78, 185-193. https://doi.org/10.1016/j.ijsu.2020.04.018

Melnyk, Yu. B., Stadnik, A. V., \& Pypenko, I. S. (2020). Resistance to post-traumatic stress reactions of vulnerable groups engaged in pandemic liquidation. International Journal of Science Annals, 3(1), 35-44. https://doi.org/10.26697/ijsa.2020.1.5

Park, S.-C., \& Park, Y. C. (2020). Mental health care measures in response to the 2019 novel coronavirus outbreak in Korea. Psychiatry Investigation, $\quad 17(2), \quad 85-86$. https://doi.org/10.30773/pi.2020.0058

Rajkumar, R. P. (2020). COVID-19 and mental health: A review of the existing literature. Asian Journal of Psychiatry, 52, 102066. https://doi.org/10.1016/j.ajp.2020.102066

Shigemura, J., Ursano, R. J., Morganstein, J. C., Kurosawa, M., \& Benedek, D. M. (2020). Public responses to the novel 2019 coronavirus (2019-nCoV) in Japan: Mental health consequences and target populations. Psychiatry and Clinical Neurosciences, 74(4), 281-282. https://doi.org/10.1111/pcn.12988

Vyas, K. J., Delaney, E. M., Webb-Murphy, J. A., \& Johnston, S. L. (2016). Psychological impact of deploying in support of the US response to Ebola: A systematic review and meta-analysis of past outbreaks. Military Medicine, 181(1112), e1515-1531. https://doi.org/10.7205/MILMED-D-15-00473

Xiong, J., Lipsitz, O., Nasri, F., Lui, L. M. V., Gill, H., Phan, L., Chen-Li, D., Iacobucci, M., Ho, R., Majeed, A., \& McIntyre, R. S. (2020). Impact of COVID-19 pandemic on mental health in the general population: A systematic review. Journal of Affective Disorders, 277, 55-64. https://doi.org/10.1016/j.jad.2020.08.001

Zandifar, A., \& Badrfam, R. (2020). Iranian mental health during the COVID-19 epidemic. Asian Journal of Psychiatry, 51, 101990. https://doi.org/10.1016/j.ajp.2020.101990

Zhang, Y., \& Ma, Z. F. (2020). Impact of the COVID-19 pandemic on mental health and quality of life among local residents in Liaoning Province, China: A cross-sectional study. International Journal of Environmental Research and Public Health, $\quad$ 17(7), 2381. https://doi.org/10.3390/ijerph17072381

\section{Cite this article as:}

Chakrabarti, S. (2021). Psychological well-being of COVID positive patients during quarantine in a South Indian Private Hospital. International Journal of Science Annals, 4(1), 34-41. https://doi.org/10.26697/ijsa.2021.1.5

The electronic version of this article is complete. It can be found online in the IJSA Archive https://ijsa.culturehealth.org/en/arhiv and in the KRPOCH Publishing Repository https://ekrpoch.culturehealth.org/handle/lib/71 